\title{
Decision-making algorithm for minimally invasive approaches to anterior skull base meningiomas
}

\author{
Malte Ottenhausen, MD, MBA, ${ }^{1}$ Kavelin Rumalla, BA, ${ }^{1}$ Andrew F. Alalade, MBBS, FRCS(SN), ${ }^{1}$ \\ Prakash Nair, MBBS, MCh(NS), ${ }^{1}$ Emanuele La Corte, MD, ${ }^{1}$ Iyan Younus, BS, ${ }^{1}$ \\ Jonathan A. Forbes, MD, ${ }^{1}$ Atef Ben Nsir, MD, ${ }^{1}$ Matei A. Banu, MD, ${ }^{2}$ Apostolos John Tsiouris, MD, ${ }^{4}$ \\ and Theodore H. Schwartz, MD1,3,5
}

\begin{abstract}
Departments of ${ }^{1}$ Neurological Surgery, ${ }^{3}$ Otorhinolaryngology, ${ }^{4}$ Radiology, and ${ }^{5}$ Neuroscience, Weill Cornell Medical College; and
\end{abstract} ${ }^{2}$ Department of Neurosurgery, Columbia-Presbyterian Medical Center, New York, New York

\begin{abstract}
OBJECTIVE Anterior skull base meningiomas are benign lesions that cause neurological symptoms through mass effect on adjacent neurovascular structures. While traditional transcranial approaches have proven to be effective at removing these tumors, minimally invasive approaches that involve using an endoscope offer the possibility of reducing brain and nerve retraction, minimizing incision size, and speeding patient recovery; however, appropriate case selection and results in large series are lacking.

METHODS The authors developed an algorithm for selecting a supraorbital keyhole minicraniotomy (SKM) for olfactory groove meningiomas or an expanded endoscopic endonasal approach (EEA) for tuberculum sella (TS) or planum sphenoidale (PS) meningiomas based on the presence or absence of olfaction and the anatomical extent of the tumor. Where neither approach is appropriate, a standard transcranial approach is utilized. The authors describe rates of gross-total resection (GTR), olfactory outcomes, and visual outcomes, as well as complications, for 7 subgroups of patients. Exceptions to the algorithm are also discussed.
\end{abstract}

RESULTS The series of 57 patients harbored 57 anterior skull base meningiomas; the mean tumor volume was $14.7 \pm$ $15.4 \mathrm{~cm}^{3}$ (range 2.2-66.1 $\mathrm{cm}^{3}$ ), and the mean follow-up duration was $42.2 \pm 37.1$ months (range 2-144 months). Of 19 patients with olfactory groove meningiomas, 10 had preserved olfaction and underwent SKM, and preservation of olfaction in was seen in $60 \%$. Of 9 patients who presented without olfaction, 8 had cribriform plate invasion and underwent combined SKM and EEA $(n=3)$, bifrontal craniotomy $(n=3)$, or EEA $(n=2)$, and one patient without both olfaction and cribriform plate invasion underwent SKM. GTR was achieved in $94.7 \%$. Of 38 TS/PS meningiomas, 36 of the lesions were treated according to the algorithm. Of these 36 meningiomas, 30 were treated by EEA and 6 by craniotomy. GTR was achieved in $97.2 \%$, with no visual deterioration and one CSF leak that resolved by placement of a lumbar drain. Two patients with tumors that, based on the algorithm, were not amenable to an EEA underwent EEA nonetheless: one had GTR and the other had a residual tumor that was followed and removed via craniotomy 9 years later.

CONCLUSIONS Utilizing a simple algorithm aimed at preserving olfaction and vision and based on maximizing use of minimally invasive approaches and selective use of transcranial approaches, the authors found that excellent outcomes can be achieved for anterior skull base meningiomas.

https://thejns.org/doi/abs/10.3171/2018.1.FOCUS17734

KEY WORDS meningioma; planum sphenoidale; olfactory groove; endoscopic; endonasal; tuberculum sella

A NTERIOR skull base meningiomas are typically benign lesions that cause symptoms from mass effect and edema in adjacent neurovascular structures, in particular the first and second olfactory nerves and the frontal lobes. Loss of olfaction, loss of vision, and neuropsychological decline are the most common symp- toms. While traditional transcranial approaches such as the pterional, bifrontal, transbasal, and orbitozygomatic techniques are effective at removing these tumors, $, 10,28,29,34$ recent years have shown the evolution and implementation of various minimally invasive approaches that benefit from the use of endoscopy and that offer the possibility

ABBREVIATIONS AWSS = anterior wall of the sphenoid sinus; EEA = endoscopic endonasal approach; EOR = extent of resection; GTR = gross-total resection; ICA = internal carotid artery; NTR = near-total resection; PS = planum sphenoidale; SKM = supraorbital keyhole minicraniotomy; TS = tuberculum sella.

SUBMITTED December 1, 2017. ACCEPTED January 16, 2018.

INCLUDE WHEN CITING DOI: 10.3171/2018.1.FOCUS17734. 
of reducing brain and nerve retraction, minimizing incision size and speeding patient recovery. These include the endoscopic endonasal approach (EEA) ${ }^{11,19,21,22,24,26}$, 32,36 and the supraorbital keyhole minicraniotomy (SKM) performed via an eyebrow incision with endoscopic assistance. ${ }^{7,15,35,40}$ However, these approaches are not suitable for all meningiomas in this location and some still benefit from more extensive, more traditional approaches. ${ }^{5-7,12}$

The goals of meningioma surgery have evolved over the years. Ideally, curative surgery requires a Simpson grade I result, including removal of the tumor, surrounding dura, and invaded bone. However, at the skull base, given the proximity of critical neurovascular structures, these goals must sometimes be modified to avoid causing harm, with the understanding that, based on the age of the patient, alternatives to surgery may include observation and also several forms of radiation therapy that have been proven to be effective. ${ }^{3,30}$ Decision-making and case selection are the keys to successful surgery, particularly when selecting appropriate cases for minimally invasive approaches so as not to compromise patient outcome.

The purpose of this article is to present and evaluate an algorithm for selecting the case-appropriate minimally invasive approach for meningiomas of the anterior skull base that we have tried to employ over the last 15 years. One critical factor that has often been overlooked, particularly for olfactory groove meningiomas, is the presence or absence of olfaction. Because loss of olfaction can have a significant negative impact on quality of life, its preservation is given a high priority in our algorithm. Outcomes with respect to extent of resection (EOR), preservation of vision, and preservation of olfaction, as well as complications, are provided for each of 7 subgroups created by the algorithm. In this way, these results can be compared with other series using different approaches or treatment strategies. We hope this article will serve as a guide regarding surgical decision-making and for success or failure of implementing minimally invasive approaches for anterior skull base meningiomas. Our aim ultimately is to provide an algorithm designed to assist surgeons in choosing the optimal approach to anterior skull base meningiomas by utilizing data from our series of patients treated for olfactory groove, tuberculum sella (TS), and planum sphenoidale (PS) tumors.

\section{Methods}

This study was approved by the Weill Cornell Medical College Institutional Review Board. We reviewed a database of prospectively acquired cases involving anterior skull base meningiomas that were managed by a single surgeon (T.H.S.) at NewYork-Presbyterian/Weill Cornell Medical College between 2008 and 2017. Our center generally uses minimally invasive approaches, either an EEA for TS or PS meningiomas or an SKM with endoscopic assistance for olfactory groove meningiomas. In some circumstances, a combined approach, pterional approach, or a bifrontal craniotomy is utilized if it is determined, based on examination of preoperative images, that the minimally invasive approach will not be suitable for achieving the goals of surgery. We have created an algorithm for determining the suitability of applying minimally invasive approaches to anterior skull base meningiomas. The algorithm was established after years of trying different approaches for different tumors and determining which approach seemed to lead to the best outcome. Once the algorithm was established, we retrospectively reviewed our cases to determine the outcomes achieved in each subgroup to establish the utility of the algorithm and our selection criteria. All patients with meningiomas arising from the olfactory groove, PS, or TS were included. A few cases were eliminated for the following reasons: In 5 cases the goal of surgery was either tumor debulking to decompress neural structures rather than gross-total resection (GTR), generally in elderly patients, or a purely intranasal meningioma recurrence in which the approach was not in question. Fifty-seven patients were divided into 7 groups based on our decision-making algorithm (Table 1). Data were collected by retrospective chart review and phone interviews with patients.

\section{Algorithm-Guided Decision-Making}

We first measured the rostrocaudal location of the tumor in relation to the attachment of the anterior wall of the sphenoid sinus (AWSS) to the anterior skull base (Fig. 1). This point divides planum and tuberculum meningiomas from olfactory groove meningiomas. Since this distinction is somewhat arbitrary, with a gray zone of tumors that arise in between, we considered tumors that had $>$ $50 \%$ of their diameter in front of this point to be olfactory groove lesions and those with $>50 \%$ of their diameter behind this point to be PS or TS meningiomas. For simplification, we combined the PS and TS meningiomas into one group since our decision-making was not influenced by this distinction. For tumors with less than $50 \%$ of tumor volume in front of the AWSS (PS and TS), we assess the lesions' lateral extension (Fig. 2). Tumors with extension lateral to the internal carotid artery (ICA), to the anterior clinoid process, or to $>5 \mathrm{~mm}$ beyond the lamina papyracea undergo a transcranial approach (Group 7), whereas all other tumors are preferably resected via an EEA (Group 6). Lesions with $>50 \%$ of tumor volume in front of the AWSS (olfactory groove) in patients with preserved olfaction are selected for SKM with endoscopic assistance (Group 5), which has as its goal complete tumor removal, including the shaving of hyperostotic bone without penetrating into the sphenoid sinus and preserving at least one olfactory nerve. However, when olfaction is lost and its preservation is no longer the goal of surgery, we evaluate the extent of cribriform plate invasion and the lateral and anterior extent of the tumor. If the cribriform plate is not invaded, then we again offer an SKM (Group 3), unless the tumor can be completely removed endonasally based on lateral and anterior extent and then we also offer an EEA as an alternative (Group 4). If the cribriform plate is clearly invaded by tumor extending into the sinuses and if it can be completely removed with EEA, we offer this approach (Group 2). However, if the tumor extends too far laterally or anteriorly for this approach to be done safely, we prefer to offer a traditional bifrontal craniotomy to fully remove the cribriform plate and reconstruction with a pericranial flap or, alternatively, 
TABLE 1. Definition of groups as seen in the algorithm flowchart

\begin{tabular}{|c|c|c|}
\hline $\begin{array}{l}\text { Group } \\
\text { No. }\end{array}$ & Approach & Requirements \\
\hline 1 & $\begin{array}{l}\text { Supraorbital approach + EEA or bicoronal } \\
\text { approach }\end{array}$ & $\begin{array}{l}\text { 1) More than } 50 \% \text { extension in front of the sphenoid sinus. 2) Impaired olfaction. 3) CP inva- } \\
\text { sion. 4) Lateral extension beyond the LP or extension to back wall of the SF. }\end{array}$ \\
\hline 2 & EEA & $\begin{array}{l}\text { 1) More than } 50 \% \text { extension in front of the sphenoid sinus. 2) Impaired olfaction. 3) CP inva- } \\
\text { sion. 4) No lateral extension beyond the LP or extension to back wall of the SF. }\end{array}$ \\
\hline 3 & Supraorbital approach + endoscopic assistance & $\begin{array}{l}\text { 1) More than } 50 \% \text { extension in front of the sphenoid sinus. 2) Impaired olfaction. 3) No inva- } \\
\text { sion of the CP. 4) Lateral extension beyond the LP or extension to back wall of the SF. }\end{array}$ \\
\hline 4 & EEA & $\begin{array}{l}\text { 1) More than } 50 \% \text { extension in front of the sphenoid sinus. 2) Impaired olfaction. 3) No inva- } \\
\text { sion of the CP. 4) No lateral extension beyond the LP or extension to back wall of the SF. }\end{array}$ \\
\hline 5 & Supraorbital approach + endoscopic assistance & 1) More than $50 \%$ extension in front of the sphenoid sinus. 2) Preserved olfaction. \\
\hline 6 & EEA & $\begin{array}{l}\text { 1) Less than } 50 \% \text { extension in front of the sphenoid sinus. 2) No lateral extension beyond } \\
\text { the ICA/LP. }\end{array}$ \\
\hline 7 & $\begin{array}{l}\text { Pterional approach, supraorbital approach, } \\
\text { subtemporal approach }\end{array}$ & $\begin{array}{l}\text { 1) Less than } 50 \% \text { extension in front of the sphenoid sinus. 2) Lateral extension beyond the } \\
\text { ICA/LP. }\end{array}$ \\
\hline
\end{tabular}

$\mathrm{CP}=$ cribriform plate.

The flowchart is shown in Fig. 3.

a combined SKM approach and an EEA to remove the tumor in the sinuses (Group 1).

Our selection criteria for the use of minimally invasive approaches in the removal of anterior skull base meningiomas is presented in Fig. 3.

\section{Surgical Technique}

Details of the surgical techniques have been described elsewhere. ${ }^{4,7,18,25,26,32,38}$ For the EEA, when resecting a PS or TS meningioma, the superior turbinates are both removed, but the middle turbinate can often be preserved, or

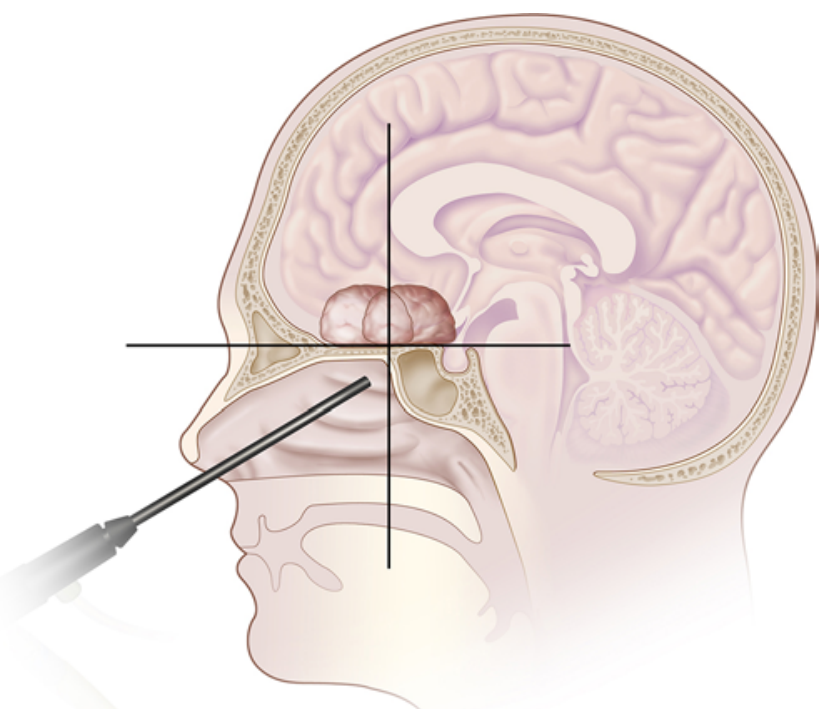

FIG. 1. Landmarks to define tumor extension: sagittal view showing the anterior margin of the sphenoid sinus (indicated by the black line perpendicular to the floor of the anterior skull base). Copyright Malte Ottenhausen. Published with permission. sometimes if the nose is narrow, only the middle turbinate on the left is removed. Since the optic canals are invaded in the majority of these tumors, we generally open the medial optic canals in all cases, particularly in treating TS meningiomas, and directly inspect the canals with angled endoscopes, removing any tumor that has invaded the canals. ${ }^{4}$ For olfactory groove meningiomas, both superior and middle turbinates are removed, as well as the septum, with a graded opening of the skull base in order to include the entire base of the tumor, including involved parts of the cribriform plate and PS and the crista galli extending laterally to the lamina papyracea, which can also be partially removed to extend the opening more laterally over the orbits. Closure includes a "gasket seal" involving onlay

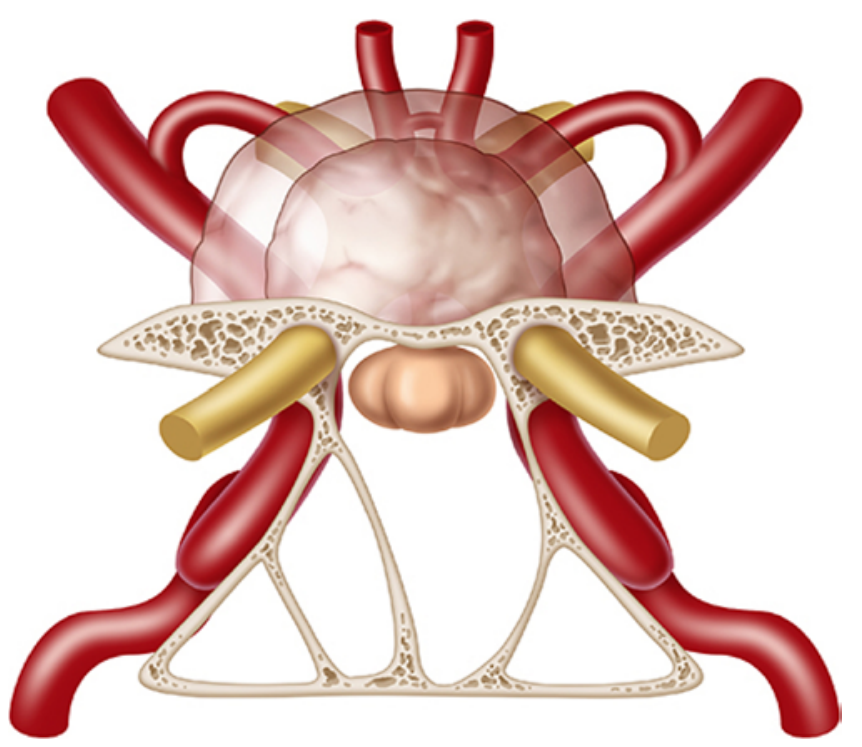

FIG. 2. Landmarks to define tumor extension: coronal view showing lateral tumor extension. Copyright Malte Ottenhausen. Published with permission. 


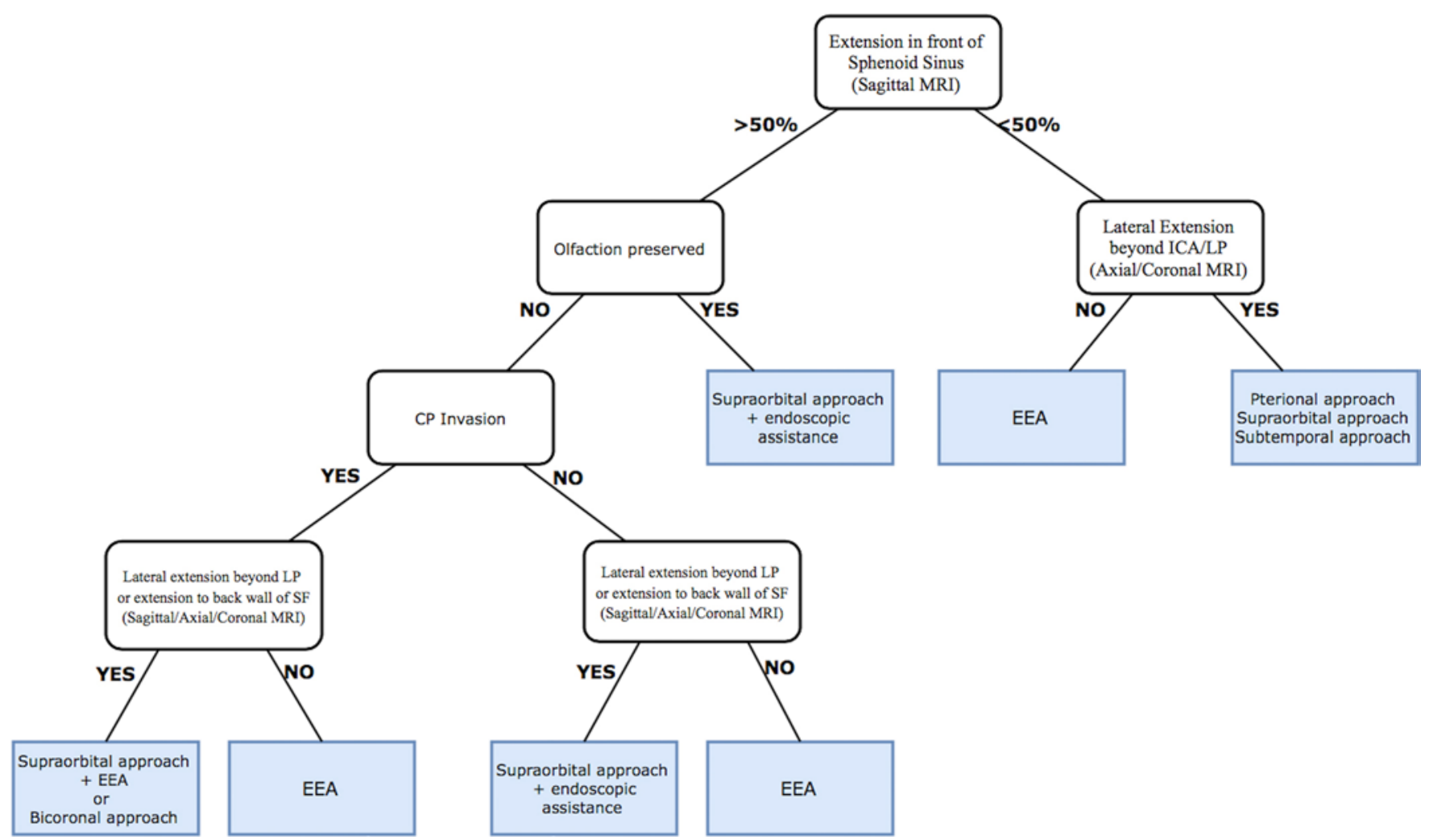

FIG. 3. Decision-making algorithm for the resection of anterior skull base meningiomas (Groups 1 [far left] to 7 [far right] are shown in blue boxes). $\mathrm{SF}=$ frontal sinus.

of fascia lata held in place with Medpore covered with a nasoseptal flap and placement of a lumbar drain for 1-2 days. ${ }^{17,27,37}$ The SKM involves an incision in the eyebrow that extends from the supraorbital notch to just beyond the superior temporal line, with a burr hole made in the pterion or "keyhole." The craniotomy includes removal of the superior rim of the orbit and drilling of the roof of the orbit. The tumor is first removed using a microscope and then with a $45^{\circ}$ endoscope to visualize the cribriform plate and the back wall of the frontal sinus. The aim is to save at least one and preferably both olfactory nerves if possible, particularly if the patient has some degree of preserved preoperative olfaction.

\section{Radiological Assessment}

Volumetric analysis was performed utilizing the Advantage Workstation (version 2.0; GE Healthcare) by a senior neuroradiologist (A.J.T.) with more than 10 years of experience. The postcontrast axial 3D T1-weighted spoiled gradient echo MR sequence was used for preoperative tumor measurement. The EOR was confirmed by comparison of preoperative and immediate postoperative contrast-enhanced MR images. EOR was categorized as GTR (100\%), near-total resection (NTR) $(\geq 95 \%$ and $<$ $100 \%)$, or subtotal resection $(<95 \%)$. The EOR of a tumor invading the optic canals was based on the visible preoperative tumor in the canals.

The Simpson grade system was not used because it was developed prior to the widespread use of MRI scans and operating microscope, and some authors feel it may not have a significant impact on outcome as previously thought. 1,13,20,31,39 Moreover, Simpson grading of skull base meningiomas can be very difficult to measure given the proximity of the foramina carrying the ICA and optic and olfactory nerves, which are never drilled out in their entirety. To avoid over- or undergrading the Simpson grade, we preferred to present the EOR for these tumors as a more accurate measure. With regards to involved bone, the EEA removes the skull base bone underlying the tumor, but not lateral dura that cannot be seen, while the SKM shaves down any hyperostosis but never fully removes involved bone to avoid CSF leak.

\section{Results}

\section{Patient and Imaging Characteristics}

Fifty-seven patients (16 male and 41 female; mean age 59.8 years [range 27-93 years]) met the inclusion criteria. The most common presenting symptoms were headaches, visual deficits, and cognitive problems. The mean followup period was $42.2 \pm 37.1$ months (range 2-144 months).

Preoperative MRI studies were available for all patients. The mean tumor volume was $14.7 \pm 15.4 \mathrm{~cm}^{3}$ (range 2.2 $\left.66.1 \mathrm{~cm}^{3}\right)$. A total of 19 tumors (31.6\%) extended more than $50 \%$ anterior to the sphenoid sinus and were classified as olfactory groove lesions, while the remaining 38 (68.4\%) were either PS or TS meningiomas. Eighteen tumors (31.6\%) invaded the cribriform plate, and 17 tumors (29.8\%) 
TABLE 2. Overview of patients and imaging characteristics by approach according to the algorithm presented

\begin{tabular}{|c|c|c|c|c|c|c|c|c|}
\hline \multirow[b]{2}{*}{$\begin{array}{l}\text { Group } \\
\text { No. }\end{array}$} & \multirow[b]{2}{*}{$\begin{array}{c}\text { No. of } \\
\text { Patients (\%) }\end{array}$} & \multirow[b]{2}{*}{$\begin{array}{l}\mathrm{M} / \mathrm{F} \\
\text { Ratio }\end{array}$} & \multirow[b]{2}{*}{ Age in Yrs* } & \multirow[b]{2}{*}{ Vol in $\mathrm{cm}^{3 *}$} & \multicolumn{4}{|c|}{ No. of Patients (\%) } \\
\hline & & & & & $\begin{array}{l}\text { Impaired } \\
\text { Vision }\end{array}$ & $\begin{array}{l}\text { Impaired } \\
\text { Olfaction }\end{array}$ & $\begin{array}{c}\mathrm{CP} \\
\text { Invasion }\end{array}$ & $\begin{array}{l}\text { Extension Lat } \\
\text { to the ICA/LP }\end{array}$ \\
\hline 1 & $6(10.5)$ & $1 / 5$ & $57.5 \pm 12.7(43-76)$ & $29.0 \pm 23.6(9.0-66.1)$ & $0(0)$ & $6(100)$ & $6(100)$ & $6(100)$ \\
\hline 2 & $2(3.5)$ & $0 / 2$ & $78.5 \pm 2.1(77-80)$ & $10.8 \pm 4.9(7.4-14.3)$ & $0(0)$ & $2(100)$ & $2(100)$ & $0(0)$ \\
\hline 3 & $1(1.8)$ & $1 / 0$ & 64 & 42.8 & $0(0)$ & $1(100)$ & $0(0)$ & $1(100)$ \\
\hline 4 & 0 & & & & & & & \\
\hline 5 & $10(17.5)$ & $1 / 9$ & $65.2 \pm 16.7(39-93)$ & $21.1 \pm 19.9(2.7-61.7)$ & $2(20)$ & $0(0)$ & $6(60)$ & $4(40)$ \\
\hline 6 & $30(52.6)$ & $11 / 19$ & $57.2 \pm 15.9(27-83)$ & $6.8 \pm 4.2(2.2-15.1)$ & $25(83.3)$ & $1(3.3)$ & $0(0)$ & $0(0)$ \\
\hline 7 & $6(10.5)$ & $2 / 4$ & $64.3 \pm 11.8(50-81)$ & $28.5 \pm 13.2(10.7-48.1)$ & $5(83.3)$ & $0(0)$ & $3(50)$ & $6(100)$ \\
\hline NA & $2(3.5)$ & $0 / 2$ & $45 \pm 19.8(31-59)$ & $6.9 \pm 3.4(4.5-9.4)$ & $2(100)$ & $0(0)$ & $0(0)$ & $2(100)$ \\
\hline
\end{tabular}

NA = not applicable.

* Values are presented as the mean $\pm \mathrm{SD}$ (range).

extended lateral to the ICA and or lamina papyracea. Table 2 provides an overview of the patients in each group.

\section{Outcome}

Outcomes are summarized in Table 3 for each group in the study.

\section{Olfactory Groove Meningiomas}

Of the 19 olfactory groove meningiomas, all were treated according to our algorithm. Of these 19 patients, 10 (52.6\%) presented with preserved olfaction and underwent an SKM (Group 5) with the goal of trying to preserve olfaction. Of these 10 patients, $6(60 \%)$ had cribriform plate invasion, but since the goal of surgery was to preserve olfaction, the supraorbital approach was used in all 6. Four of the 10 patients $(40 \%)$ had extension of the lesion beyond the reaches of an EEA and the lateral extension could be removed easily through the supraorbital approach. One of these patients also had decreased vision. A GTR was achieved in $90 \%$ of these patients. This implies that al- though preoperative images were interpreted as showing cribriform plate invasion, the SKM procedure is capable of removing enough tumor that the postoperative MR image appears not to show any tumor and the hyperostosis can be thinned to normal thickness. The one patient with residual tumor was found to have residual hyperostosis in the cribriform plate, which was followed on imaging for 5 years without evidence of any interval growth. Olfaction was preserved in $6(60 \%)$ of these 10 patients and vision was worse in 1 , stable in 8 , and improved in 1.

Six patients had loss of olfaction, cribriform plate invasion, and tumor extending beyond the reach of the EEA (Group 1). In this group, since olfaction was already lost, the goal of surgery was to remove the entire cribriform plate. Hence, these patients were not candidates for an SKM alone. Since the EEA would not be capable of allowing removal of the entire tumor given the lesion's lateral extension, these patients were candidates for either a bifrontal craniotomy or a combined SKM/EEA. In this group, patients were indeed treated with either a bifron-

TABLE 3. Outcomes by approach according to decision-making algorithm

\begin{tabular}{|c|c|c|c|c|c|}
\hline Group No. & No. of Patients (\%) & EOR & Visual & Olfaction & CSF Leak \\
\hline 1 & $6(10.5)$ & GTR $100 \%(n=6)$ & Stable $100 \%(n=6)$ & Impaired $100 \%(n=6)$ & None \\
\hline 2 & $2(3.5)$ & GTR $100 \%(n=2)$ & Stable $100 \%(n=2)$ & Impaired $100 \%(n=2)$ & None \\
\hline 3 & $1(1.8)$ & GTR 100\% (n=1) & Stable $100 \%(n=1)$ & Impaired $100 \%(n=1)$ & None \\
\hline 4 & 0 & & & & \\
\hline \multirow[t]{3}{*}{5} & $10(17.5)$ & GTR $90 \%(n=9)$ & Improved $10 \%(n=1)$ & Preserved $60 \%(n=6)$ & None \\
\hline & & NTR $10 \%(n=1)$ & Stable $80 \%(n=8)$ & Impaired 40\% (n= 4) & \\
\hline & & & Worse $10 \%(n=1)$ & & \\
\hline \multirow[t]{3}{*}{6} & $30(52.6)$ & GTR $100 \%(n=30)$ & Improved $53.3 \%(n=16)$ & Preserved $63.3 \%(n=19)$ & 1 case \\
\hline & & & Stable $43.3 \%(n=13)$ & Impaired $36.7 \%(n=11)$ & \\
\hline & & & Worse $3.3 \%(n=1)$ & & \\
\hline \multirow[t]{2}{*}{7} & $6(10.5)$ & GTR $83.3 \%(n=5)$ & Improved $33.3 \%(n=2)$ & Preserved $33.3 \%(n=2)$ & None \\
\hline & & NTR $16.7 \%(n=1)$ & Stable $66.6 \%(n=4)$ & Impaired $66.6 \%(n=4)$ & \\
\hline \multirow[t]{2}{*}{ NA } & $2(3.5)$ & GTR $50 \%(n=1)$ & Improved $50 \%(n=1)$ & Preserved $50 \%(n=1)$ & None \\
\hline & & NTR $50 \%(n=1)$ & Stable $50 \%(n=1)$ & Lost $50 \%(n=1)$ & \\
\hline
\end{tabular}


tal craniotomy $(n=3)$ or SKM plus EEA $(n=3)$. In this group, GTR was achieved in all patients, olfaction was permanently lost, as expected, and there was a single case of mucocele.

Two patients with impaired olfaction, cribriform plate invasion, and tumors amenable to an EEA (Group 2) underwent the EEA. GTR was achieved in each patient, but in 1 case a postoperative hematoma developed that required the patient to undergo reoperation. Olfaction was lost, as expected, in all of these patients. One patient without olfaction and without cribriform plate involvement but who harbored a tumor that extended laterally underwent SKM (Group 3). A GTR was achieved. No patient was categorized into Group 4 (loss of olfaction without cribriform plate invasion and without lateral extent [i.e., a tumor that was amenable to an EEA]). Overall, for the 19 patients with olfactory groove meningiomas, we were able to utilize a minimally invasive approach in $84.2 \%(16 / 19)$ and radiological GTR was achieved in $94.7 \%$ (18/19) of the entire group and in $93.75 \%(15 / 16)$ of those in whom a minimally invasive approach could be used. EEA alone was only used in $10.5 \%(2 / 19)$.

\section{PS and TS Meningiomas}

Of the 38 PS/TS meningiomas, 36 were treated according to our algorithm. Of these, $30(83.3 \%)$ of these were amenable to, and underwent, minimally invasive EEA (Group 6). A GTR was achieved in $100 \%$. Vision was improved in $16(53.3 \%)$ of 30 patients, stable in $13(43.3 \%)$, and worse in $1(3.3 \%)$. The reoperation rate for a CSF leak was $0 \%$, there was $1 \mathrm{CSF}$ leak that was repaired by delaying the placement of a lumbar drain. Six patients had lateral extension of the tumor beyond the reach of an EEA and underwent a craniotomy (Group 7). Of these, 3 patients $(50 \%)$ had cribriform plate extension. A GTR was achieved in $5(83.3 \%)$. In the 1 patient with NTR, a small residual tumor was left behind along the cribriform plate. Vision was improved in 2 patients $(33.3 \%)$ and stable in 4 (66.7\%). Olfaction was worse in 4 patients $(66.7 \%)$. One patient had a postoperative hematoma.

\section{Cases That Did Not Fit the Algorithm}

In 2 patients with PS meningiomas, the actual surgical approach used differed from the algorithm. One patient with impaired vision, preserved olfaction, and no anterior extension was operated via the EEA despite the fact that the tumor had lateral extension past the ICA and appeared to encase the ICAs and anterior cerebral arteries $>180^{\circ}$. This patient would have been offered a pterional approach according to the algorithm, but the patient preferred to undergo surgery via the EEA. Surprisingly, a GTR was achieved. Cases such as these demonstrate that the EEA may be capable of allowing removal of tumors that encase blood vessels and extend lateral to the ICA in certain circumstances in which a suitable plane of dissection can be found and utilized. Moreover, encasement of the ICA was not $360^{\circ}$, and thus the tumor could be rolled over the top of the ICA. However, it is hard to predict in which cases this will occur, and certainly it is safer to offer a transcranial approach, although EEA might prove sufficient for success.
The second patient with impaired vision, preserved olfaction, and no cribriform plate invasion who was operated on via the EEA had tumor lateral to the ICA over anterior clinoid segment on one side. The patient had improved vision, but a small residual amount of tumor left behind over the anterior clinoid segment was followed for 9 years; a slight interval growth appeared, and the lesion was removed through a craniotomy.

\section{Discussion}

In most surgical fields, there has been an evolution toward increasing application of minimally invasive approaches, which have been shown to speed recovery, reduce operative risks, and lead to comparable or, in some cases, improved outcomes. ${ }^{2}$ Neurosurgery is no exception, and procedures that involve embolization, radiosurgery, and minimal access and keyhole surgery with endoscopic assistance are salient examples. Anterior skull base meningiomas are challenging tumors that abut the olfactory and optic nerves, compress the frontal lobes, and invade the nasal sinuses and optic canals. Traditional approaches such as the pterional, bifrontal, transbasal, and orbitozygomatic are effective at removing these tumors, ,10,28,29,34 although the morbidities attendant on brain retraction, sagittal sinus transection, optic nerve manipulation, and wound healing offer room for improvement. In recent years, we have witnessed the evolution and implementation of a variety of minimally invasive approaches that benefit from the use of endoscopy and that may avoid some of these issues, reduce morbidity, and speed recovery. These include the EEA ${ }^{11,19,21,22,24,26,32,36}$ and the SKM performed via an eyebrow incision. ${ }^{7,15,35,40}$ While attractive in theory, not all anterior skull base meningiomas are amenable to minimally invasive approaches, and there is a lack of consensus regarding case selection. Most centers tend to favor one or the other approach and apply this approach universally to all tumors, rather than adopting a strategy of careful case selection based on a set of defined criteria. In this article we show the results of having implemented such a treatment algorithm. We successfully used minimally invasive approaches in $85 \%$ of our cases, and we achieved GTR in $96 \%$ of all cases and in $98 \%$ of all minimally invasive cases. However, these results do not provide long-term follow-up data, and it is possible that a small residual tumor below the resolution of MRI could recur given long enough follow-up.

The primary criticism of these minimally invasive approaches is that, as a result of the more limited field of view, the rate of Simpson grade I resections will be lower. However, the literature does not support this criticism. Simpson grading was developed in 1957, and with the advent of modern neurosurgical tools and radiation therapy, the outcome for grade I, II, and III resections are essentially equivalent. ${ }^{13,33,39}$ Moreover, for skull base meningiomas in particular, attempting to achieve a higher Simpson grade may result in decreases in quality of life such as anosmia, CSF leak, and decreases in visual acuity. ${ }^{13}$ If one uses radiological GTR rather than Simpson grade as a metric of successful surgery, the results of our minimally invasive approaches are comparable, if not superior, to the 
published literature. However, tumor invading the optic canals may be difficult to appreciate on MRI. With standard transcranial surgery, GTR is achieved in $92.3 \%$ of the cases of olfactory groove meningiomas and in $84.1 \%$ of the cases of PS and TS meningiomas. ${ }^{13,23}$ Using our algorithm, the results are slightly better for both olfactory groove meningiomas and TS/PS meningiomas. Moreover, we preserved olfaction in $60 \%$ of patients who had preoperative olfaction intact in the olfactory group and preserved or improved vision in $97.5 \%$ of those with TS or PS meningiomas. In a series of 41 microsurgically treated patients with long-term follow-up, Bassiouni et al. reported preserved olfaction in $24.4 \%$ of patients and improved vision in $83.3 \% .^{8}$ In their series of 24 patients with TS meningiomas operated via the frontobasal interhemispheric approach, Ganna et al. reported improved vision in $79 \%$ of patients. ${ }^{16}$ Gande et al. reported no deterioration of olfaction after stereotactic radiosurgery in a group of patients with olfactory groove meningiomas. ${ }^{14}$

We also wish to emphasize that alternative treatment strategies can lead to similar results. For example, while we prefer to use an EEA for TS and PS meningioma, other surgeons favor SKM. Our reason for selecting the EEA is the high rate of medial optic canal invasion, which we think is best addressed by opening the medial optic canals, a procedure that can be challenging through a keyhole minicraniotomy. Likewise, a tumor extending down into the sella may be difficult to reach through a supraorbital approach. Likewise, some surgeons prefer the EEA for olfactory groove meningiomas. However, the literature shows that the EOR is only $66.7 \%$ for this approach and olfaction is universally lost. ${ }^{24}$ For this reason, we prefer the supraorbital minicraniotomy, which leads to higher rates of GTR with less morbidity? ${ }^{7}$ Nevertheless, there are clearly other algorithms that can be applied and other approaches that will also lead to excellent outcomes; this paper serves to demonstrate the results of one particular algorithm as a benchmark for comparisons and as a teaching tool for how these decisions are made at an experienced center.

\section{Conclusions}

Minimally invasive approaches can be utilized, along with more traditional transcranial approaches, in the management of anterior skull base meningiomas. Using a simple algorithm aimed primarily at maintaining quality of life through preservation of olfaction and vision, high rates of GTR can be achieved with acceptable morbidity.

\section{References}

1. Ajler P, Beltrame S, Massa D, Tramontano J, Baccanelli M, Yampolsky C: [Relevance of Simpson's grades in the resection of grade I meningiomas.] Surg Neurol Int 8 (Suppl 2):S5-S10, 2017 (Span)

2. Antoniou SA, Lasithiotakis K, Koch OO, Antoniou GA, Pointner R, Granderath FA: Bibliometric analysis of scientific contributions in minimally invasive general surgery. Surg Laparosc Endosc Percutan Tech 24:26-30, 2014

3. Astradsson A, Wiencke AK, Munck af Rosenschold P, Engelholm SA, Ohlhues L, Roed H, et al: Visual outcome after fractionated stereotactic radiation therapy of benign anterior skull base tumors. J Neurooncol 118:101-108, 2014
4. Attia M, Kandasamy J, Jakimovski D, Bedrosian J, Alimi M, Lee DL, et al: The importance and timing of optic canal exploration and decompression during endoscopic endonasal resection of tuberculum sella and planum sphenoidale meningiomas. Neurosurgery 71 (1 Suppl Operative):58-67, 2012

5. Attia M, Patel KS, Kandasamy J, Stieg PE, Spinelli HM, Riina HA, et al: Combined cranionasal surgery for sphenoorbital meningiomas invading the paranasal sinuses, pterygopalatine, and infratemporal fossa. World Neurosurg 80:e367-e373, 2013

6. Bander ED, Singh H, Ogilvie CB, Cusic RC, Pisapia DJ, Tsiouris AJ, et al: Endoscopic endonasal versus transcranial approach to tuberculum sellae and planum sphenoidale meningiomas in a similar cohort of patients. J Neurosurg 128:40-48, 2018

7. Banu MA, Mehta A, Ottenhausen M, Fraser JF, Patel KS, Szentirmai O, et al: Endoscope-assisted endonasal versus supraorbital keyhole resection of olfactory groove meningiomas: comparison and combination of 2 minimally invasive approaches. J Neurosurg 124:605-620, 2016

8. Bassiouni H, Asgari S, Stolke D: Olfactory groove meningiomas: functional outcome in a series treated microsurgically. Acta Neurochir (Wien) 149:109-121, 2007

9. Bitter AD, Stavrinou LC, Ntoulias G, Petridis AK, Dukagjin M, Scholz M, et al: The role of the pterional approach in the surgical treatment of olfactory groove meningiomas: a 20year experience. J Neurol Surg B Skull Base 74:97-102, 2013

10. Ciurea AV, Iencean SM, Rizea RE, Brehar FM: Olfactory groove meningiomas: a retrospective study on 59 surgical cases. Neurosurg Rev 35:195-202, 2012

11. Conger AR, Lucas J, Zada G, Schwartz TH, Cohen-Gadol AA: Endoscopic extended transsphenoidal resection of craniopharyngiomas: nuances of neurosurgical technique. Neurosurg Focus 37(4):E10, 2014

12. de Almeida JR, Carvalho F, Vaz Guimaraes Filho F, Kiehl TR, Koutourousiou M, Su S, et al: Comparison of endoscopic endonasal and bifrontal craniotomy approaches for olfactory groove meningiomas: a matched pair analysis of outcomes and frontal lobe changes on MRI. J Clin Neurosci 22:17331741,2015

13. Ehresman JS, Garzon-Muvdi T, Rogers D, Lim M, Gallia GL, Weingart J, et al: The relevance of Simpson grade resections in modern neurosurgical treatment of world health organization grade I, II, and III meningiomas. World Neurosurg 109:e588-e593, 2018

14. Gande A, Kano H, Bowden G, Mousavi SH, Niranjan A, Flickinger JC, et al: Gamma Knife radiosurgery of olfactory groove meningiomas provides a method to preserve subjective olfactory function. J Neurooncol 116:577-583, 2014

15. Gandhoke GS, Pease M, Smith KJ, Sekula RF Jr: Supraorbital versus endoscopic endonasal approaches for olfactory groove meningiomas: a cost-minimization study. World Neurosurg 105:126-136, 2017

16. Ganna A, Dehdashti AR, Karabatsou K, Gentili F: Frontobasal interhemispheric approach for tuberculum sellae meningiomas; long-term visual outcome. Br J Neurosurg 23:422-430, 2009

17. Garcia-Navarro V, Anand VK, Schwartz TH: Gasket seal closure for extended endonasal endoscopic skull base surgery: efficacy in a large case series. World Neurosurg 80:563-568, 2013

18. Greenfield JP, Anand VK, Kacker A, Seibert MJ, Singh A, Brown SM, et al: Endoscopic endonasal transethmoidal transcribriform transfovea ethmoidalis approach to the anterior cranial fossa and skull base. Neurosurgery 66:883-892, 2010

19. Hayhurst C, Sughrue ME, Gore PA, Bonney PA, Burks JD, Teo C: Results with expanded endonasal resection of skull 
base meningiomas technical nuances and approach selection based on an early experience. Turk Neurosurg 26:662-670, 2016

20. Heald JB, Carroll TA, Mair RJ: Simpson grade: an opportunity to reassess the need for complete resection of meningiomas. Acta Neurochir (Wien) 156:383-388, 2014

21. Jones SH, Iannone AF, Patel KS, Anchouche K, Raza SM, Anand VK, et al: The impact of age on long-term quality of life after endonasal endoscopic resection of skull base meningiomas. Neurosurgery 79:736-745, 2016

22. Khan OH, Anand VK, Schwartz TH: Endoscopic endonasal resection of skull base meningiomas: the significance of a "cortical cuff" and brain edema compared with careful case selection and surgical experience in predicting morbidity and extent of resection. Neurosurg Focus 37(4):E7, 2014

23. Komotar RJ, Starke RM, Raper DM, Anand VK, Schwartz TH: Endoscopic endonasal versus open transcranial resection of anterior midline skull base meningiomas. World Neurosurg 77:713-724, 2012

24. Koutourousiou M, Fernandez-Miranda JC, Wang EW, Snyderman $\mathrm{CH}$, Gardner PA: Endoscopic endonasal surgery for olfactory groove meningiomas: outcomes and limitations in 50 patients. Neurosurg Focus 37(4):E8, 2014

25. Kulwin C, Schwartz TH, Cohen-Gadol AA: Endoscopic extended transsphenoidal resection of tuberculum sellae meningiomas: nuances of neurosurgical technique. Neurosurg Focus 35(6):E6, 2013

26. Laufer I, Anand VK, Schwartz TH: Endoscopic, endonasal extended transsphenoidal, transplanum transtuberculum approach for resection of suprasellar lesions. J Neurosurg 106:400-406, 2007

27. Leng LZ, Brown S, Anand VK, Schwartz TH: "Gasket-seal" watertight closure in minimal-access endoscopic cranial base surgery. Neurosurgery 62 (5 Suppl 2):ONSE342-ONSE343, 2008

28. Nakamura M, Struck M, Roser F, Vorkapic P, Samii M: Olfactory groove meningiomas: clinical outcome and recurrence rates after tumor removal through the frontolateral and bifrontal approach. Neurosurgery 60:844-852, 2007

29. Nanda A, Maiti TK, Bir SC, Konar SK, Guthikonda B: Olfactory groove meningiomas: comparison of extent of frontal lobe changes after lateral and bifrontal approaches. World Neurosurg 94:211-221, 2016

30. Navarria P, Pessina F, Cozzi L, Clerici E, Villa E, Ascolese AM, et al: Hypofractionated stereotactic radiation therapy in skull base meningiomas. J Neurooncol 124:283-289, 2015

31. Otero-Rodriguez A, Tabernero MD, Munoz-Martin MC, Sousa P, Orfao A, Pascual-Argente D, et al: Re-evaluating Simpson Grade I, II, and III resections in neurosurgical treatment of World Health Organization grade I meningiomas. World Neurosurg 96:483-488, 2016

32. Ottenhausen M, Banu MA, Placantonakis DG, Tsiouris AJ, $\mathrm{Khan} \mathrm{OH}$, Anand VK, et al: Endoscopic endonasal resection of suprasellar meningiomas: the importance of case selection and experience in determining extent of resection, visual improvement, and complications. World Neurosurg 82:442-449, 2014
33. Oya S, Kawai K, Nakatomi H, Saito N: Significance of Simpson grading system in modern meningioma surgery: integration of the grade with MIB-1 labeling index as a key to predict the recurrence of WHO Grade I meningiomas. J Neurosurg 117:121-128, 2012

34. Pallini R, Fernandez E, Lauretti L, Doglietto F, D'Alessandris QG, Montano N, et al: Olfactory groove meningioma: report of 99 cases surgically treated at the Catholic University School of Medicine, Rome. World Neurosurg 83:219-231, 231.e1-231.e3, 2015

35. Romani R, Lehecka M, Gaal E, Toninelli S, Celik O, Niemelä M, et al: Lateral supraorbital approach applied to olfactory groove meningiomas: experience with 66 consecutive patients. Neurosurgery 65:39-53, 2009

36. Schroeder HW: Indications and limitations of the endoscopic endonasal approach for anterior cranial base meningiomas. World Neurosurg 82 (6 Suppl):S81-S85, 2014

37. Schwartz TH, Fraser JF, Brown S, Tabaee A, Kacker A, Anand VK: Endoscopic cranial base surgery: classification of operative approaches. Neurosurgery 62:991-1005, 2008

38. Singh H, Essayed WI, Jada A, Moussazadeh N, Dhandapani S, Rote S, et al: Contralateral supraorbital keyhole approach to medial optic nerve lesions: an anatomoclinical study. J Neurosurg 126:940-944, 2017

39. Sughrue ME, Kane AJ, Shangari G, Rutkowski MJ, McDermott MW, Berger MS, et al: The relevance of Simpson Grade I and II resection in modern neurosurgical treatment of World Health Organization Grade I meningiomas. J Neurosurg 113:1029-1035, 2010

40. Telera S, Carapella CM, Caroli F, Crispo F, Cristalli G, Raus L, et al: Supraorbital keyhole approach for removal of midline anterior cranial fossa meningiomas: a series of 20 consecutive cases. Neurosurg Rev 35:67-83, 2012

\section{Disclosures}

T.H.S. is a consultant for Elliquence and owns stock in Visionsense.

\section{Author Contributions}

Conception and design: Schwartz, Ottenhausen. Acquisition of data: Ottenhausen, Rumalla, Alalade, Nair, La Corte, Younus, Forbes, Nsir, Banu. Analysis and interpretation of data: Schwartz, Forbes, Tsiouris. Drafting the article: Ottenhausen, Rumalla, Banu. Critically revising the article: Schwartz. Reviewed submitted version of manuscript: Schwartz. Approved the final version of the manuscript on behalf of all authors: Schwartz. Administrative/technical/material support: Tsiouris. Study supervision: Schwartz.

\section{Correspondence}

Theodore H. Schwartz: Weill Cornell Medicine, New York, NY. schwarh@med.cornell.edu. 